\title{
A CADAVERIC STUDY ON THE ANATOMICAL VARIATIONS OF THE MUSCULOCUTANEOUS NERVE IN RELATION WITH MEDIAN NERVE AND CORACOBRACHIALIS MUSCLE
}

\author{
Alok Tripathi, Hina Kausar, Saurabh Arora, Satyam Khare, Shilpi Jain, Ram Kumar Kaushik, Ajay Kumar \\ *Department of Anatomy, Subharti Medical College, Meerut, UP, India
}

\begin{abstract}
Introduction: Musculocutaneous nerve is derived from the lateral cord of brachial plexus and supplies the muscles of the arm. Initially the nerve accompanies the lateral side of third part of axillary artery and then pierces the coracobrachialis muscle after supplying it, passes downwards and laterally in between biceps brachii and brachialis sending branches to both and continues as lateral cutaneous nerve of the forearm. Variations of musculocutaneous nerve is important for surgeons, orthopedic surgeons and traumatologists, so a detailed cadaveric study of musculocutaneous nerve was done to observe the variations.
\end{abstract}

Material \& Methods: Musculocutaneous nerve was studied in 50 human cadavers (30 males and 20 females) of age group 40-60 years at Department of Anatomy, Subharti Medical College, Meerut, India.

Results: Musculocutaneous nerve was present in all the cases and was piercing the coracobrachialis muscle. In $4 \%$ of the cases, the nerve was rejoining the median nerve after piercing the coracobrachialis.

Keywords: Musculocutaneous nerve, median nerve, coracobrachialis.

\section{INTRODUCTION}

Variations in the terminal branches of the cords of brachial plexus are common and reported in literature. Variations of musculocutaneous nerve and its branches have been reported previously. The musculocutaneous nerve may be found absent in some studies. Some authors observed that the musculocutaneous nerve do not pierce the coracobrachialis [1-3].

The musculocutaneous nerve may be found absent in some studies [1, 4-7]. Some authors also observed that the musculocutaneous nerve joins the median nerve after piercing coracobrachialis muscle $[1,7-9]$. So, a detailed study was done for the observation of variations of musculocutaneous nerve in human cadavers.

\section{MATERIALS AND METHODS}

Hundred upper Limbs (Rt-50 Lt-50) from fifty embalmed human cadavers (30 males and 20 females) of age group 40-60 years were dissected and observed for a period of four year. The pectoral region, axilla, arm and forearm region were dissected to observe the cords of brachial plexus and the variations of musculocutaneous nerve were observed.

\section{OBSERVATIONS AND RESULTS}

The musculocutaneous nerve was present in all the limbs. In all the cases, musculocutaneous nerve was originating from lateral cord and was piercing the coracobrachialis muscle. In two cases, musculocutaneous nerve was observed to join the median nerve after piercing coracobrachialis muscle on both the sides ( $4 \%$ of cases). The lateral root of median nerve from the lateral cord was small in both the cases (Fig. 1\&2).

\section{Address for Correspondence:}

Dr Hina Kausar, Assistant Professor, Department of Anatomy, Subharti Medical College, Swami Vivekanand Subharti University, N.H.-58, Delhi-Haridwar By Pass Road, Meerut, UP, India- 250005. Mob: 9897209556 E-mail: tabish322@gmail.com 


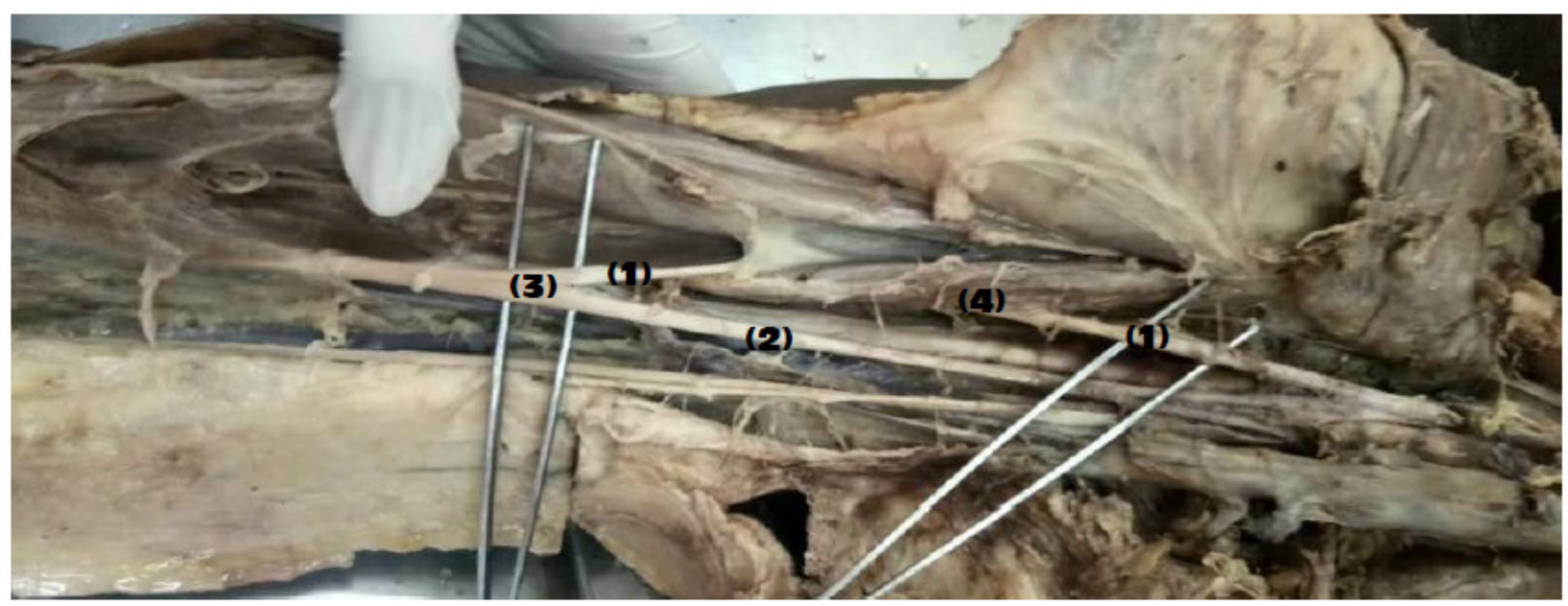

Fig. 1 : Photograph showing joining of Musculocutenous Nerve with Median Nerve after piercing Coracobrachialis Muscle (Right Limb).
(1). Musculocutenous Nerve
(2). Median Nerve
(3). Joining of Musculocutenous Nerve \& Median Nerve

\section{(4). Coracobrachialis Muscle}

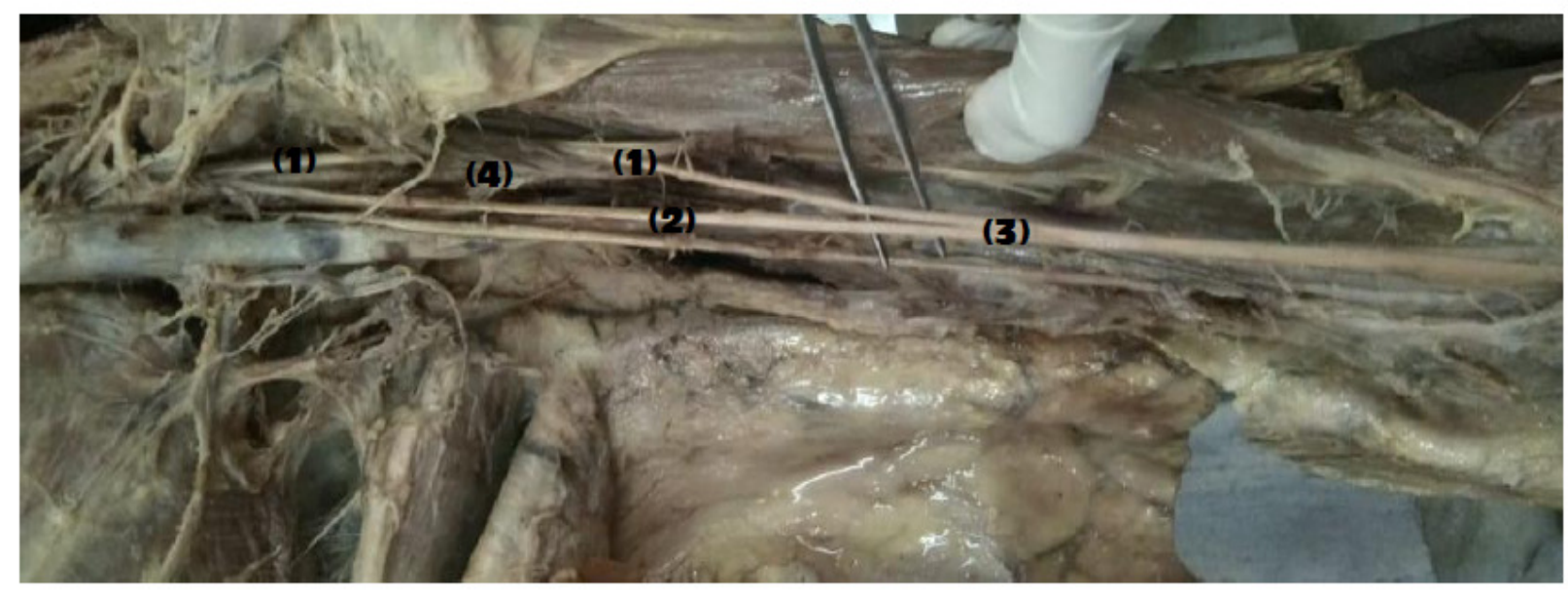

Fig. 2 : Photograph showing joining of Musculocutenous Nerve with Median Nerve after piercing Coracobrachialis Muscle (Left Limb).
(1). Musculocutenous Nerve
(2). Median Nerve
(3). Joining of Musculocutenous Nerve \& Median Nerve
(4). Coracobrachialis Muscle

\section{DISCUSSION}

The musculocutaneous nerve arises from lateral cord of brachial plexus, innervates the muscles of the arm and pierces the coracobrachialis muscle and continues as lateral cutaneous nerve of the forearm [10]. The

musculocutaneous nerve has frequent variations. It may run behind coracobrachialis or adhere for some distance to the median nerve and pass behind biceps. Another variation in which the musculocutaneous nerve did not pierce the coracobrachialis (Table 1) but rather pass between it and the biceps, and in some 
Variations of the musculocutaneous nerve......

cases the nerve split, one part going superficial to the muscle and the other through the muscle [11]. Prasada and Chaudhary (2001) reported two cases of absent musculocutaneous nerve from lateral cord of brachial plexus [4].

Ihunwo et al. (1997) reported a case of the bilateral absence of the musculocutaneous nerve from the lateral cord of the brachial plexus [5] (Table 2). But in our study the musculocutaneous nerve was present in all the cases. The musculocutaneous nerve was rejoining the median nerve after piercing coracobrachialis muscle was reported by Joshi et al. (2008) in one case [8] and in $3.125 \%$ of cases reported by Bhattarai and Poudel (2009) [9] (Table 3). But in our study we observed the joining of musculocutaneous nerve with median nerve after piercing coracobrachialis muscle in $4 \%$ of the cases bilaterally. Iwata (1960) explained on the embryological basis that the brachial plexus appeared as a single radicular cone in the upper limb, which was divided into ventral and dorsal segments.

The ventral segments gave roots to the median and ulnar nerve. The musculocutaneous nerve arose from the median nerve [12] Jamuna and Amudha (2011) reported three cases of absent musculocutaneous nerve unilaterally and in $2 \%$ of limbs the nerve was rejoining median nerve after piercing coracobrachialis [1] (Table 2,3).

But in our study in all the cases musculocutaneous nerve was present. Nakatani et al. (1997) and Le Minor (1990) observed the absence of the musculocutaneous nerve from the lateral cord of the brachial plexus [6,7] (Table 2). Nayak et al. (2006) reported that in one limb, the musculocutaneous nerve had a low origin and that the nerve was not piercing the coracobrachialis [2]. In present study, the musculocutaneous nerve was present in all the cases and was found to pierce the coracobrachialis muscle. Chitra (2007) observed in two cases that the musculocutaneous nerve did not pierced the coracobrachialis [3]. Thakur et al. (2015) observed musculocutaneous nerve not piercing coracobrachialis in $7.5 \%$ cases [13] and Babu et al. (2016) in $4 \%$ of the cases [14].

\section{Table 1: Comparison of studies on musculocutaneous nerve not piercing coracobrachialis}

\begin{tabular}{|l|c|}
\hline Authors & $\begin{array}{c}\text { Percentage of } \\
\text { cases observed }\end{array}$ \\
\hline Jamuna \& Amudha (2011) [1] & $6 \%$ \\
\hline Nayak et al. (2006) [2] & $1.66 \%$ \\
\hline Chitra (2007) [3] & $4 \%$ \\
\hline Present study (2018) & $0 \%$ \\
\hline
\end{tabular}

Table 2: Comparison of studies on absence of musculocutaneous nerve

\begin{tabular}{|l|c|}
\hline Authors & $\begin{array}{c}\text { Percentage of } \\
\text { cases observed }\end{array}$ \\
\hline $\begin{array}{l}\text { Prasada \& Chaudhary (2001) } \\
{[4]}\end{array}$ & $3 \%$ (Bilaterally) \\
\hline Ihunwo et al. (1997) [5] & $1 \%$ (Bilaterally) \\
\hline Jamuna \& Amudha (2011) [1] & $2 \%$ (Bilaterally) \\
\hline Nakatani et al. (1997) [6] & $1 \%$ (Unilaterally) \\
\hline Le Minor (1990) [7] & $1 \%$ (Unilaterally) \\
\hline Present study (2018) & $0 \%$ \\
\hline
\end{tabular}

Table 3: Comparison of studies on rejoining of musculocutaneous nerve with median nerve after piercing coracobrachialis muscle

\begin{tabular}{|l|c|}
\hline Authors & $\begin{array}{c}\text { Percentage of } \\
\text { cases observed }\end{array}$ \\
\hline Joshi et al. (2008) [8] & $1 \%$ \\
\hline Bhattarai \& Poudel (2009) [9] & $3.125 \%$ \\
\hline Jamuna \& Amudha (2011) [1] & $2 \%$ \\
\hline Le Minor (1990) [7] & $3 \%$ \\
\hline Present study (2018) & $4 \%$ \\
\hline
\end{tabular}

\section{CONCLUSION}

Variations of musculocutaneous nerve are common and the knowledge of these variations are important for surgeons. It can be concluded from the present 
study that variations are not uncommon in musculocutaneous nerve and in our study in $4 \%$ of the cases, the musculocutaneous nerve were found to rejoin the median nerve after piercing coracobrachialis.

\section{REFERENCES}

1. Jamuna $M$, Amudha $G$. A cadaveric study on the anatomic variations of the musculocutaneous nerve in the infraclavicular part of the brachial plexus. J Clin Diag Res. 2011 (Suppl-1); 5 (6):1144-1147.

2. Nayak S, Samuel VP, Somayaji N. Concurrent variations of the median nerve, the musculocutaneous nerve and the biceps brachii muscle. Neuroanatomy. 2006; 5:30-2.

3. Chitra R. Multiple bilateral neuroanatomy variations of the nerves of the arm. Neuroanatomy. 2007; 6:43-5.

4. Prasada Rao PV, Chaudhary SC. Absence of the musculocutaneous nerve: Two case reports. Clin Anat. 2001; 14:31-5.

5. Ihunwo AO, Osinde SP, Mukhtar AU. Distribution of median nerve to the muscles of the anterior compartment of the arm. Cent Afr J Med. 1997; 43:359-60.
6. Nakatani T, Mizukami S, Tanaka S. Three cases of the musculocutaneous nerve not perforating the coracobrachialis muscle. Acta Anat Nippon. 1997s; 72:191-4.

7. Le Minor JM. A rare variation of the median and the musculocutaneous nerve in man. Archives Anatomy Histology Embryology. 1990; 73:33-42.

8. Joshi SD, Joshi SS, Athavale SA. Hitch-hiking fibers of the lateral cord of the brachial plexus in search of their destination. J Anat Soc India. 2008; 57:26-9.

9. Bhattarai C, Poudel PP. Unusual variations in the musculocutaneous nerves. Kathmandu University Medical Journal. 2009; 7: No. 4 (28): 408-10.

10. Standring S. Gray's Anatomy- The anatomical basis of clinical practice. $40^{\text {th }}$ ed., London: Elsevier Churchill Livingstone. 2008; 724-28.

11. W. Henry Holinshed. Anatomy for surgeons: vol.3 (The Back and Limbs). $3^{\text {rd }}$ ed., Philadelphia, Harper \& Row. 366, 1982.

12. Iwata $\mathrm{H}$. Studies on the development of the brachial plexus in Japanese embryos. Rep Dept Anat Mie Prefect Univ Sch Med. 1960; 13: 129-44.

13. Thakur KC, Jethani SL, Parsad V. Non piercing variation of musculocutaneous nerve. JEMDS. 2015; 4 (90): 15515-15517.

14. Babu DJ, Pillai TJ, Priyanka KD, Jalaja Y, Kumar US. A study on variations of musculocutaneous nerve in adult cadavers, IOSR-JDMS. 2016; 15 (5): 14-17. 